Research Paper

\title{
THE SCIENTIFIC AND PRACTICAL FOUNDATIONS FOR SUSTAIN- ABLE DEVELOPMENT AND CLIMATE CHANGE RESPONSE IN MEKONG DELTA, VIETNAM
}

\author{
Mai Trong Nhuan', Nguyen Tai Tue ${ }^{1,2}$, Luu Viet Dung', Tran Dang Quy ${ }^{1,2}$
}

ARTICLE HISTORY

Received: October 12, 2019 Accepted: November 05, 2019

Publish on: December 25, 2019

\section{ABSTRACT}

Mekong Delta in Vietnam plays an important role of national economy and has highly diverse natural conditions and resources. In the context of climate change, sea level rise, and increasing the impacts from water utilization in the upstream Mekong River and natural resource exploitation within Mekong Delta, it is needed to have the scientific and practical foundations, strategies, solutions and models for large scale transformation in Mekong Delta towards sustainability and climate change response. However, the combination of the existing dam systems and water utilization from upstream of Mekong River have caused a quick decline of sediments and water discharge into the Mekong Delta. Additionally, the unsustainable use of natural resources within Mekong Delta is directly threatening the sustainable development. Therefore, it is needed to implement: i) integrating solutions of policies, integrated strategies, models and solutions to large scale transformation of socio-economic models; nature and ecosystem based sustainable natural resource use planning for proactive response to climate change and human impacts; ii) ensuring non-traditional security, smart response to climate change and disasters and other negative impacts in Mekong
Delta; iii) enhancing science and technologies, human resource development and smart governance. Besides, it needs to promote international cooperation for building "Smart water governance in Mekong River and Delta" for sustainable development and climate change response.

Keywords: Climate change, Mekong Delta, Transformation, Sustainable development.

\section{Introduction}

Mekong Delta (MD) in Vietnam has 13 provinces and cities, with a total population of 17.66 million people, accounting for $19 \%$ total population of Vietnam, with a population density of 433 people $/ \mathrm{km}^{2}$ (GSO, 2016). The MD is the biggest rice producer area in Vietnam, plays an important role for socio-economic development of Vietnam. In term of economic development, the MD contributes an important proportion in the overall national economy. However, its economic development is not commensurate with favorable natural conditions and rich in natural resources. In recent decade, climate change, sea-level rise and increasing in number of dam construction in the upstream of the Mekong River have caused the integrated impacts from climate change and anthropogenic activities for the MD.

Consequently, the MD has been reported to

$\triangle$ MAI TRONG NHUAN

Corresponding author: mnhuan@yahoo.com

${ }^{1}$ Key Laboratory of Geoenvironment and Climate change Response

${ }^{2}$ Faculty of Geology, VNU University of Science 
be one of three most vulnerable delta plain to climate change in the world. Therefore, it is urgently needed to implement research programs and research projects for gaining the scientific and practice foundations for enhancing sustainable development of the MD. This paper aims to analyze and evaluate the natural characteristics, natural resources, environment and climate change; strategies, policies and development models in the MD for proposing solutions, orientation and models for comprehensive sustainable development, effective response to integrated impacts and ensured non-traditional security in the MD.

2. Natural characteristics, natural resources and environment in mekong delta

\subsection{Natural characteristics}

2.1.1 Evolution of geology and geomorphology

Since about 20 thousand years before present (B.P.), global sea level started to increase continuously at a rapid rate, up to 8000 years B.P., when the sea level decreased slowly to at a rate of approximately $2 \mathrm{~mm} /$ year (Nittrouer et al., 2017). The reduction of the global sea level rise has created conditions for the delta plain to develop. During this period, the MD was expanded and accreted in a total length of $200 \mathrm{~km}$ from the Cambodian border to the present coast during a period of nearly 2000 years from 5500 to 3500 years BP (Anthony et al., 2015; Oanh and Lap, 2008). Total area of the MD was formed to be approximately of $62.520 \mathrm{~km}^{2}$ (Truong et al., 2011). The average elevation of the MD is less than $2 \mathrm{~m}$ in height in comparison to mean sea level (Nittrouer et al., 2017).

Geomorphological characteristics of the MD are divided into two distinguished parts, consisting of the high elevation delta plain and the low delta plain. The high elevation delta plain is strongly influenced by river development, which is developed in swamps and inundated floodplains with elevation of $0.5 \mathrm{~m}-1.5 \mathrm{~m}$ and delim- ited by Late Pleistocene formation with elevations of $3 m-5 m$ in the Cambodian border. The high elevation delta plain extends through An Giang, Dong Thap, Can Tho, Hau Giang, Vinh Long, Long An, Tien Giang and Kien Giang provinces(Hoang et al., 2016). The low delta plain is strongly influenced by the wave and tidal regime and charaterizes by sand dune systems with the elevation of $3 \mathrm{~m}-10 \mathrm{~m}$ in height, which distribute parallelly to the shoreline in the direction of North East - South West, between the sand dunes is the lowlands with the elevation of $1.5 \mathrm{~m}-2.5 \mathrm{~m}$ in height (Oanh and Lap, 2008). The low delta plain includes the coastal areas of Long An, Ben Tre, Tra Vinh, Soc Trang, Bac Lieu and Ca Mau province (Hoang et al., 2016). The coastal area from Long An province to Bac Lieu province is strongly influenced by wave regime, so the accretion rate of the land toward the sea is approximately $16 \mathrm{~m} /$ year. While the $\mathrm{Ca}$ Mau peninsula is strongly influenced by the tidal regime, so it can extened toward the sea upto 26 m/year năm (Anthony et al., 2015; Liu et al., 2017).

2.1.2 Reduction of suspended sediments transported by river systems

Major dam systems on the upper MD were started to build in the year 1993 by China (Manwan dam). By April 2016, a total of 35 dams were built for the purposes of electricity production and agricultural irrigation, water supply and others. In the future, there will have more 226 dams that are proposed to build (Allison et al., 2017). Before the dam systems were built, the suspended sediment transported by Mekong River was estimated to be 160 million tons. However, after the Manwan dam was built, the suspended sediment in river was significantly reduced in the downstream of the dam (Wang et al., 2011). Further studies by Kondolf et al. (2014) demonstrated that if all dams are being constructed and put into operation, $51 \%$ of the suspended sediment transported by the Mekong River downstream will be reduced; and if all the planted dams will be constructed, $96 \%$ of the 
suspended sediment transported by Mekong River will be reduced. The reduction of suspended sediments transported downstream will cause significant impact on the stability of river flows, canal flows and geological and geomorphological evolution of the MD (Nittrouer et al., 2017), affecting soil fertility, ecosystems and natural aquatic productivity in the MD (Pukinskis, 2013).

\subsubsection{Shoreline erosion characteristics}

There are many studies on the characteristics of shoreline erosion in the MD. Results from analysis of SPOT 5 high resolution satellite images demonstrated the changing of shoreline in different subzones. The estuarine subzone composes mainly by sand, the East coast and West coast is formed by mud (Anthony et al., 2015). The mud coasts are being eroded at a rate of about $50 \mathrm{~m} /$ year, of which $90 \%$ of the length of the mud coasts in the East coastline are eroded. The total area of eroded land is estimated to be 5 $\mathrm{km}^{2}$ during a period from $2003-2012$. In the estuarine area, the annual accretion area is significantly reduced from $0.78 \mathrm{~km}^{2}$ to $0.26 \mathrm{~km}^{2}$ during above period. The major causes for increased coastal erosion are the reduction of sediment supply from the river, sand extraction in rivers and canals, and increased surface subsidence (Anthony et al., 2015).

\subsubsection{Salinity intrusion}

Coastal salinization can occur in two major mechanisms, saline intrusion of surface water at river mouths, and salinization of groundwater. In the MD, salinity intrusion into the delta plains is occurring very seriously and increased rapidly over time. The estuarine areas where significantly increase in salinity are Vam Co Tay, Tien River, Ham Luong River, Co Chien, and coastal plains of Tra Vinh, My Tho and Ca Mau provinces. Some areas have high salinity in water reached to $30 \%$ in Thuan An $(6 \mathrm{~km}$ far from the coastline), 27.6\% in Ben Trai (12 km far from the coastline), 9.5\% in Tra Vinh (Duc et al., 2008). The delta plain area affected by salinity and alkalinity in the MD has increased rap- idly in recent years. The main causes of salinity intrusion is due to the low terrain and rapid decline of river water caused by upstream dam systems. Salinity intrusion accurs rapidly and expands in area if the flood season in the MD is abnormally late. Other causes such as aquaculture in the Mekong Delta have caused large amounts of seawater to spill over into the surrounding areas (Tho et al., 2014).

\subsection{Characteristics of the main types of nat- ural resources}

\subsubsection{Land resources}

Total natural land area of the MD is nearly 4 million hectares, accounting for $12 \%$ of the total land area of the country. The total land area using for agriculture and aquaculture is about 2.6 million ha. In which, the proportion of annual crop land accounts for greater than $50 \%$, consisting of paddy land $>90 \%$, land for cultivation of crops and short-term industrial crops of about 150,000 ha, perennial cops of 320,000 ha (Communist Review, 2017). The main characteristics of the soil groups in the MRD are shown as follows: alluvial soil accounts for about 1.2 million ha, with high natural fertility and no serious limiting factors; alkaline soil (1.6 million ha), which is characterized by high acidity, high aluminum concentration and low phosphorus. This soil group also includes saline and heavy saline soils. The alkaline soil distributes in Dong Thap Muoi and Long Xuyen quadrangle. The salty alkaline soil is concentrated in the central part of $\mathrm{Ca} \mathrm{Mau}$ peninsula. Saline soil ( 0.75 million ha) is affected by salinity intrusion during the dry season. These land areas can hardly be supplied with fresh water. Other soils (0.35 million ha), including peatland (U Minh forest), gray soil on ancient alluvial soil (northern of MD) and hilly land (west-north of MD).

\subsubsection{Water resources}

\section{a. Surface water resources}

MD has a entangled system of rivers, streams and canals, with major river systems of the Tien and Hau rivers that segregate to discharge into the sea at following estuaries Co Chien River, 
Ham Luong River, Ba Lai River, Cua Dai River and Cua Tieu and Hau Rivers through Dinh An and Tran De. Hydrological regimes in the MD are directly affected by upstream flow, tidal regime in the East Sea and West Sea. Annually, the Mekong River transports about $475 \mathrm{~km}^{3}$ of water into the MD (Yadu et al., 2018) and the total amount of rainwater within the MD is about 52 billion $\mathrm{m}^{3}$. The average annual flow discharge into the MD is about $12,900 \mathrm{~m}^{3} / \mathrm{s}$, in which an amount of $10,100 \mathrm{~m}^{3} / \mathrm{s}$ occurs in Tan Chau station and of $2,800 \mathrm{~m}^{3} / \mathrm{s}$ occurs in Chau Doc station. Most of the inflow occurs during the flood season, accounting for $90 \%$, while the rest occurs during the dry season (Tran, 2014).

In recent years, the total flood flows discharge into the MD being tended to decrease at an average rate of 1.87 billion $\mathrm{m}^{3}$. The total flows during the flood season in the years of 2010, 2012, 2015 and 2016 were significantly declined in comparison to the average value of many years, accounted only for $75-90 \%$ of the average value of many years, causing a decline in water stockpiles for the dry season. Total flows during the dry season flows in the MD has a decrease tendency, with an annual rate of about 0.18 billion $\mathrm{m}^{3}$ (equivalent to about $11.7 \mathrm{~m}^{3} / \mathrm{s}$ ). Total flows during the dry season in the years of 2010,2013, 2015 and 2016 were much smaller than the multi-year average, accounted for only $75-90 \%$ of the multi-year average, causing severe drought and water shortage (Tran, 2014).

\section{b. Groundwater resources}

The MD has a great potential for groundwater resources, with five to seven groundwater layers, distributed in the depth from a few dozen meters to $500-600 \mathrm{~m}$. The areas with high groundwater potential are Bac Lieu, Long An, Dong Thap, Ca Mau, Tra Vinh and Can Tho. The total natural reserve is approximately 21 million $\mathrm{m}^{3}$ /day (MRC, 2010). Groundwater plays an important role in supplying water for urban, rural and industrial use in the MD. About $80 \%$ rural population is using the groundwater, many urban areas such as Soc Trang, Bac Lieu, Ca Mau and
Tra Vinh depend entirely on the groundwater). For the whole MD, there are about 2 million wells to exploit the groundwater. Of which there are over 550,000 large drilled wells that are exploiting a total water volume of two million $\mathrm{m}^{3} /$ day (MRC, 2010).

Due to the large scale of exploitation, most the groundwater level of the aquifers in the MD tends to be depressed rapidly with an average rate from 0.2 to $0.4 \mathrm{~m} /$ year, with a maximum of $0.93 \mathrm{~m} /$ year. The major cause of the depressed groundwater level is the continuously increase in exploitation of the groundwater of both numbers and sizes of wells (MRC, 2010).

\subsubsection{Biodiversity and ecosystems}

The MD has a high level of biodiversity of both the number of species (fauna and flora) and ecosystems. Ecosystems are classified into tidal, sand dunes, and swamp in the coastal plains, estuarine areas, floodplains, large lowland areas, peat swamps, stripes of land alluvial riverbank and ancient alluvial terrace. Aquatic ecosystems are divided into freshwater aquatic ecosystems, including the upper stream Mekong river, Vam Co Tay, the Thuong, the Lower, Cai Co and Long Khot rivers and large natural lakes, wetlands and semi-subsurface waterways, lowland areas, riverside alluvial areas, protected and protected areas, canals and agricultural production facilities; the brackish-water and saline-water ecosystems in the coastal areas include the mouths of the Mekong river and the canals near the sea. The ecosystems in each region of the MD are characterized by the regimes of flooded, submerged, and tidal areas (Tri, 2015).

Coastal mangrove ecosystems: Mostly distributed in the coastal areas of the MD, most developed mangroves are concentrated in the Mekong River estuaries and Ca Mau Peninsula.

Melaleuca forest ecosystem: In the past, Melaleuca forest covered half of the area of alum soil, but now it is only distributed in U Minh peat areas and some places in Dong Thap Muoi and Ha Tien plains. The ecosystem plays an important role in stabilizing soil, hydrological regimes 
and the conservation of animals.

The fauna of the MD consists of 23 mammal species, 386 species and orders of bird, 6 amphibian species and 260 species of fish. The largest number and diversity of fauna are often observed in the Melaleuca and mangrove forests. The fish fauna of the MD contains 216 species belonging to 60 families, 19 orders (Tri, 2015).

\subsection{The natural factors affecting sustainable} development of the Mekong Delta

Based on the research results, the MD is a dynamic system that has developed and evolved continuously from 8.000 years ago. The amount of suspended sediment transported by the Mekong River into the MD is one of among important factors for delta evolution and expansion towards the sea, in which approximately one-third of such transported sediments will be deposited in the estuaries and near shore sea to form the delta front (Nittrouer et al., 2017), to reduces hore line erosion and land surface subsidence. In addition, the suspended sediment transported by the river directly contributes to stabilize the geomorphological streams, canals and to develop the agriculture. Another important factor for the evolution of the MD is the water transported from the outside Vietnam by the river systems. Freshwater flows in the river system directly contribute to maintain the aquatic biodiversity in water bodies, creating different ecological habitats and ecosystems, promoting the socio-economic development in the MD. Additionally, flows in river and canal systems can directly flush the seawater intrusion toward the sea.

In recent decades, the dam and water regulation construction in the upstream of the MD have significantly reduced the mass of suspended sediments and water flows in the Mekong River to the MD.These factors certainly affect the natural development of the MD, contributing to increase severe erosion of shoreline and riverbank, land subsidence, inundation, and salinity intrusion, shortage of freshwater and fertilized alluvium for the natural ecosystems, agriculture, industry and other socio-economic activities.
Therefore, it is necessary to implement the researches that will determinethe scientific and practical foundation to response to unfavorable conditions in order to enhance resilience, adaptation and sustainable development in the MD.

\section{Policies, strategies and sustainable de- velopment models for the mekong delta}

After "Innovation" period, the MD has made a remarkable change and plays an important role in the socio-economic development of Vietnam. Parallel with the rapid development of industrial and service activities, the agricultural share is continuously decreasing. Currently, the provinces in the MD occupy for approximately $20 \%$ GDP, $57 \%$ rice production and $56 \%$ aquaculture production in the total production of Vietnam (GSO, 2015b). However, other sectors, including health, education, trained labor force and the level of poverty reduction in the MD are quite low in comparison to the national average, affecting the socio-economic development in the context of climate change. Nowadays, the agricultural and aquaculture production of the MD are facing many risks, including lack of the land resources and financial capital,weak development of science and technology, shortage in information and difficulty in accessing the market directly; competition in the international market on price and international quality of the production, limited storage capacity of production, and heavily depending on seasonal crops (Renaud and Kuenzer, 2012). Besides, the impacts related to climate change, the decline of water resources from upstream, sea level rise and salt intrusion have also put more pressure on the development of the MD (Smajgl and Ward, 2013), affecting the transformation of the model, the socio-economic development plan of the regions.

\subsection{Transforming agricultural production}

The transformation of agriculture in the MD will highly depend on policies, development of irrigation systems, and soil and water environment (Renaud and Kuenzer, 2012). Three major 
agricultural transformation periods in the $\mathrm{MD}$ are presented as follows (Renaud and Kuenzer, 2012):

- From 1975 to 1990: Rice cultivation area was expanded due to the development of the irrigation system (irrigated rice cultivation area annually increased about $85.000 \mathrm{ha}$ ). In this period, the rice cultivation was extensively developed for 2-3 crops per year.

- From 1991 to 1999: Rice cultivation for export was priority developed due to the socio-economic transformation (post 1986) and development of irrigation infrastructure to ensure drainage, irrigation, dike construction and minimize salinization. The MD plays as major region to contribute the share of rice export of Vietnam to be one of the largest rice exporters in the world.

- From to 2000- now: This period is observed as highly development of intensive and extensive aquaculture which has a higher value than the rice farming. The aquaculture is mainly grown fish Pangasius, basa fish in fresh water, tiger shrimp (as Penaeusmonodon) in brackish water. Additionally, this period is also promoted the fruit trees with high economic values, including mango, rambutan, durian, etc. However, the extensively development of the aquaculture caused the degradation of coastal ecosystems, particularly mangroves and increased the high risks to the local people.

Nevertheless, agricultural and aquaculture activities are strongly influenced from climate change and degradation of water resources transported from the Mekong River (Smajgl and Ward, 2013). Negative impacts such as shortage of water resources, decreasing water flows and quality, salinity intrusion have increased the vulnerability for agriculture and aquaculture development, directly affecting livelihoods and degradation of economic potential of people in the MKD. As a result, agricultural and aquaculture development in the MD must be transformed into new development model for better response to impacts from climate change and shortage of water resources.

3.2 Reclamation strategy, migration of people in new economic development programs in the Mekong Delta

From 1975 to 2000, the migration flows to the MD under several new economic development programs that have motivated economic growth for the whole region with high commodity agricultural production (Anh, 2010). The most intensive migration of people to the MD was taken place during the period from 1975-1986 and the period from 1986-1995 (Anh, 2010). Due to the favor condition for the agricultural development and available of natural resources, the total migrants to the MD markedly increased annually. Although the migration policies have many advantages for socio-economic development in the region, but there also brought many negative impacts on natural resources and environment such as the destruction of inland wetland ecosystems and coastal mangrove forests. These activities have brought immediately economic benefits, but it has caused a degradation of the resilience of the natural and social systems to climate change, influencing non-traditional security, increasing the vulnerability of the local communities, particularly in the coastal area (Cosslett and Cosslett, 2013; Renaud and Kuenzer, 2012).

However, in recent years, the migration trend in the Mekong Delta has obviously increased (GSO, 2015a; Renaud and Kuenzer, 2012). Migration is a consequence of the transformation of the socio-economic model in the Mekong Delta in both urban and rural areas (Entzinger and Scholten, 2016). A specific example, such as the shift from rice cultivation to aquaculture or agricultural mechanization will increase the number of unemployed workers, promoting migration of these workers to other areas. Other reasons to promote migration are also evident in the desire of many households when they want to have stable career in urban areas and large cities with high incomes. Another source of remittances to the Mekong Delta gradually increased over the years leading to the transformation of the eco- 
nomic model and job of many households (Renaud and Kuenzer, 2012; World Bank, 2016). In summary, migration has played an important role in the development of the MD in history, but it has become a challenge for maintaining socioeconomic development in the present period.

\subsection{Industrialization}

Currently, there are 74 industrial areas and 214 industrial clusters in the Mekong Delta (https://goo.gl/bGvX8C). However, the total value of industrial production of the region accounted for only a small proportion of the country. Major industries of the MD are food processing, producing materials and consumer goods, lacking high engineering and technology sectors. The reasons of poor development of industrial activities include (Renaud and Kuenzer, 2012): The potential of businesses and the private sectors has not been effectively used as a motive force for industrial development; human resources, particular high-technology human resources is relatedly low. The level of creativity and technology is weak, the scientific and technological capacity of the MD must be strengthened; Infrastructure should be investigated intensively to make as a driving force for industrial development.

\subsection{Urbanization}

Urbanization is an important driver for socioeconomic development in the MD. With four large urban centers My Tho, Long Xuyen, Rach Gia, Vinh Long and a central urban Can Tho city where are surrounded by industrial areas and clusters, seaports to form regional links in socioeconomic development. However, development plans and strategies for urban construction in the MD are less sustainable, particularly vulnerable to climate change and non-traditional security (water conflict in the border, free migration) (Renaud and Kuenzer, 2012; Smajgl and Ward, 2013). Therefore, urbanization will play acrucial role in the MD, contributing to the economic restructure in the region towards sustainable development.

3.5 Strategy for agricultural and aquacul-

\section{ture development}

The strategy for agricultural and aquaculture development has been carried out in each periodwith the overall goal that were transformed from ensuring food security (through rice production) to the harmonious development between value of economic and quality of agricultural and aquatic products with national interests and community benefits. Therefore, the agriculture and aquaculture development strategy for the MD was promulgated in Decision No. 639 /QD-BNN-KH dated 02/04/2014 of the Ministry of Agriculture and Rural Development. Generally, the main objective of the strategy is "Developing comprehensive, sustainable agriculture and rural areas in the MD with highadaptability to climate change; effective producing with high quality and competitiveness; the sensible economic structure and production organization; modernizing the socio-economic infrastructure gradually; increasing the income and living standard of citizens; using natural resources effectively; protecting and improvingthe environment" (https://goo.gl/sXhPoU).

Therefore, the transformation of the economic structure between agriculture and aquaculture with high adaptation to climate change will be the future development model of the MD.

\subsection{Strategies for industry and services de- velopment}

The development strategy for industry and services is an important part of the MD's socioeconomic development plan approved by the Prime Minister with Decision No. 939/QD-TTg dated July 19, 2012 (https://goo.gl/hXg5MU). The Mekong Delta's industrial and service development orientations are closely linked with processing industries of agricultural, forestry and fishery products in the export; power and energy industries, textile and footwear industry, mechanical industry, commercial services andtourism services. In general, the service industry development strategies of the MD willpriority for agriculture and light industry, developing energy to 
ensure national energy security. However, the issue of a sustainable water development strategy in the MD is facing many difficulties due to crossborder water security issues.

\subsection{Strategy for using and exploiting natural resources}

Strategiesfor using and exploitingnatural resource in the MD a concentrated in two main objectives: water and mineral resources (construction sands). However, the issue of strategy'sdevelopment for sustainable water resources using in the Mekong Delta is facing many difficulties due to transboundary water security issues (the construction of upstream dams) and the context of climate change impacts (salinity intrusion, sea level rise, etc.) (Cosslett and Cosslett, 2013; Smajgl and Ward, 2013). In addition, the degradation of transported sediments in the MD leads to the loss of construction sand and to increase erosion of riverbanks and shoreline, resulting in loss of land for economic development. Therefore, the strategy for sustainable exploitation of water resource and minerals need to enhance sustainable use of these natural resources, to enhance the resilience with climate change and non-traditional security but must be also integrated, closely linked to the national strategy.

\subsection{Impact of changes in policy and strate-} gies for socio-economic development in the Mekong Delta

According to the analysis of changes in socioeconomic factors and strategic policy for the $\mathrm{MD}$, the important factors in the development of theregion's economy are agriculture and aquaculture (Stewart and Coclanis, 2011). The most important factor of socio-economic development of the MD highly depends on the conversion of wet rice cultivation into higher economic forms such as aquaculture and fruit trees planting. The food processing industry also develops in the region but its share in the total economy is still small. Urbanization and the increase in services are limited, below the region's potential. In the current characteristics of the MD, there are chal- lenges to balanced development between market economy, private enterprises and international integration (Renaud and Kuenzer, 2012). In addition, factors such as salinity intrusion, water shortage, phenomena related to climate change have a strong impact on socio-economic development in the MD and the region's sustainable development goals. Therefore, in order to achieve the SDGs for the MD, it is necessary to make development plans and synchronous management among different departments and sectors, especially under the impacts of climate change and non-traditional security scenarios.

\section{Orientations, models and solutions to to-} wards sustainable development in the Mekong Delta

\subsection{General principles}

The general principles for developing solutions to model of sustainable development in the MD should be based on three main factors: water resources, sediment transported from Mekong River and human resource development. In which, water and sediments are importantly initial inputs to maintain the balance of the dynamic natural system of the MD, being important resources for socio-economic development. Another factor of human resources will determine the management and utilization of natural resources and better response to challenges of climate change. However, the scenarios for water resources and sediments will tend to follow the factors:

- The flow and quality of water resourcesin the MD are both decreasing;

- The suspended sediments transported by Mekong River to the MD tend to be decreasing;

- Hazards such assea level rise, riverbank erosion, shoreline erosion, land subsidence, salinity intrusion is increasing in both scale and intensity;

- The benefits and challenges from sea water/brackish water resources to the MD are increasing to impact significantly, leading to shift 
the coastal and estuarine ecosystems;

- Human activities at the upstream of Mekong river are difficult to predict and control.

Thus, the overall solutions to ensure national security and response to climate change, minimize the impact of natural disasters on the MD need to be in harmony between socio-economic development and the environmental protection including: 1) Harmony between nature, socioeconomy, and humanity; 2) Application of science and technology to sustainable exploitation of natural resources; 3) Harmonization in the policy for all stakeholders,and 4) Enhancement of resilience and adaptation to vulnerable factors (salinity intrusion, water source security, migration, etc.).

\subsection{Recommended solutions to sustainable} development for Mekong Delta in the context of climate change

\subsubsection{Policy solutions}

- Development policy on regional integration, especially to respond to natural disasters and climate change such as salinity intrusion, drought, water shortage, to develop the master plan and apply to the whole region's economy in order to encourage the exchange and support among provinces and cities in the overall goals of the sustainable development of the MD;

- Policy on encouraging and supporting farmers to transform the agriculture in term of shift the traditional into new plants and animals and change their careers accordingly;

- Policy on encouraging enterprises to invest in production of agricultural materials (currently foreign enterprises are dominant) and processing high-quality products to increase the added value of products.

- Prohibition against exploiting sand in main canals;

- Policy on reducing ground water exploitation;

- Develop, conserve and plant new coastal mangrove forest.

4.2.2 Scientific and technological solutions

- To build and complete the infrastructure sys- tem of freshwater reservoirs in the delta area and conserve the existing wetlands in order to ensure the replenishment of fresh water during the dry season;

- To construct sea and river dyke systems with the ensure the principle of circulating water sources from rivers to the sea, avoiding the inundation of waterways in the delta area;

- To conserve and replant new mangrove forests for reducing greenhouse gas emissions and increasing sedimentation and protect the coastlines;

- To develop infrastructure for strengthening the regional integration in socio-economic development and respond to climate change, nontraditional security;

- To research and develop plans that are highly adaptable to changing environmental conditions, especially salinity intrusion;

- To develop simulating models to have scientific foundation for developing long-term response plans;

- To evaluate changes in terrains, geomorphology, hydrology, navigation and evolution in the MD based on GIS and high-resolution remote sensing technologies;

- To implement a real-time monitoring network for proper and sustainable water allocation and utilization.

4.3 Solutions for training human resources and smart governance for climate change

4.3.1 Solutions for training high-quality human resources

- To invest in development of human resources in research institutes and universities in the fields of smart climate change response to climate change in the MD;

- To invest in development of undergraduate and graduate programs in universities; education curricula in schools about the smart response to climate change in the MD.

4.3.2 Solutions to governance of smart response toclimate change

- To invest in researching solutions to increase the governance capability of smart re- 
sponses to climate change for managers at all levels;

- To invest in the research and development of high-quality human resources for the management of projects related to climate change in the $\mathrm{MD}$;

- To research on the overall strategy of active response to climate change, wise use of natural resources, environmental protection for sustainable development of the MD.

4.3.3 Diplomatic and international cooperation

- To negotiate with countries in the upstream Mekong river to reduce the number of dams in the upstream and reduce the hydrological adjustment of the Mekong river;

- To support Cambodia in the protection of Tonlesap Lake;

- To support Laos in sustainable economic development based on non-hydropower;

- To cooperate with Laos, Thailand and China in the exchange of flow data, flow coordination, ensuring no-impacts on the fish migration and sediment flow to the MD.

\section{Conclusions}

The MD has an evolution based on a "dynamic system" with major components to stabilize its natural development being water flow and sediments transported by the Mekong river system. These natural processes have been occurring for the last 8,000 years but will be strongly affected by the decline in river flow from the upstream, sea level rise and human activities in the current socio-economic development scenarios. Degradation in river flows from upstream will result in decreasing water resources and nutrients for ecosystems' development, rapid degradation of ecosystems, and increasing salinity intrusion. The decrease of sediment sources will cause instability of riverbank, coastlines, surface subsidence and deterioration in the quality of land resources in the MD. These challenges together with sea level rise and climate change will bring great chal- lenges for sustainable development. Therefore, it is necessary to implement policies, scientific and technological solutions, education and training human resources and smart governance. Besides, it is necessary to promote extensively and comprehensively diplomatic solutions and extensive international cooperationto leadthe MD towards "Smart Water Resourcesgovernance" for sustainable development.

\section{Acknowledgements}

This paper is supported by the government project "Studying and assessing the impacts of climate change, disasters, human activities for proposing solutions and sustainable development models in adjacent areas of Song Hau”, code BDKH.39/16-20.

\section{References}

1. Allison, M.A., Nittrouer, C.A., Ogston, A.S., Mullarney, J.C., Nguyen, T.T., 2017. Sedimentation and Survival of the Mekong Delta: A Case Study of Decreased Sediment Supply and Accelerating Rates of Relative Sea Level Rise. Oceanography, 30 (3): 98-109.

2. Anh, D.N., 2010. Migration policies to build new economic zones in Vietnam.

3. Anthony, E.J., Brunier, G., Besset, M., Goichot, M., Dussouillez, P., Nguyen, V.L., 2015. Linking rapid erosion of the Mekong River delta to human activities. Scientific Reports, 5: 14745. https://doi.org/10.1038/srep14745

4. Cosslett, T.L., Cosslett, P.D., 2013. Water resources and food security in the Vietnam Mekong Delta. Springer Science \& Business Media.

5. Duc, N.A., Savenije, H.H.G., Pham, D.N., Tang, D.T., 2008. Using salt intrusion measurements to determine the freshwater discharge distribution over the branches of a multi-channel estuary: The Mekong Delta case. Estuarine, Coastal and Shelf Science, 77 (3): 433-445.

6. Entzinger, H., Scholten, P., 2016. Adapta- 
tion to climate change through migration: A case study of the Mekong Delta: IOM.

7. GSO, 2015a. National Internal Migration Survey Report, printed Ke, T.C.T., ed.: Hanoi, Statistical Publishing House.

8. GSO, 2015b. Statistical Yearbook, printed Statistics, T.C.T., ed.: Hanoi, Statistical Publishing House.

9. GSO, 2016. Statistical Yearbook, summary, in Ke, T.C.T., ed.: Hanoi, Statistical Publishing House.

10. Hoang, T.M., Van Lap, N., Oanh, T.T.K., Jiro, T., 2016. The influence of delta formation mechanism on geotechnical property sequence of the late Pleistocene-Holocene sediments in the Mekong River Delta. Heliyon, 2 (11): e00165.

11. Kondolf, G., Rubin, Z., Minear, J., 2014. Dams on the Mekong: cumulative sediment starvation. Water Resources Research, 50 (6): 51585169.

12. Liu, J.P., DeMaster, D.J., Nguyen, T.T., Saito, Y., Nguyen, V.L., Ta, T.K.O., Li. X., 2017. Stratigraphic Formation of the Mekong River Delta and Its Recent Shoreline Changes: Oceanography, 30.

13. MRC, 2010. Water Basin Status Report (2010 Summary), Vientiane.

14. Nittrouer, C.A., Mullarney, J.C., Allison, M.A., Ogston, A.S., 2017. Sedimentary processes building a tropical delta yesterday, today, and tomorrow: The Mekong system.

15. Oanh, T.T.K., Lap, N.V., 2008. Mekong Delta Development Process during the Holocene, in Proceedings of the First National Conference Report: Vietnam Marine Geology \& Sustainable Development, Ha Long: 297-301.

16. Pukinskis, I., 2013. Mekong Sediment Basics (Vietnamese Language).

17. Renaud, F.G., Kuenzer, C., 2012. The Mekong Delta system: Interdisciplinary analyses of a river delta, Springer Science \& Business Media.

18. Smajgl, A., Ward, J., 2013. The waterfood-energy nexus in the Mekong region: Assessing development strategies considering cross-sectoral and transboundary impacts, Springer Science \& Business Media.

19. Stewart, M.A., Coclanis, P.A., 2011. Environmental change and agricultural sustainability in the Mekong Delta, Springer Science \& Business Media.

20. Communist Review, 2017. Sustainable development of land resources in the Mekong Delta.

21. Tho, N., Merckx, R., Ut, V., 2014. Impacts of saline water irrigation and shrimp pond discharges on the surrounding waters of a coastal district in the Mekong delta of Vietnam: Environmental Earth Sciences, 71 (5): 2015-2027.

22. Tran, H.T., 2014. Project report: Studying the effects of climate change on water resources change in the Mekong Delta. Code: Climate change.BDKH.08/16-20, Vietnam Institute of Meteorology, Hydrology and Environment.

23. Tri, T.N., 2015. Research on biodiversity of fish in the Mekong Delta and their changes due to the impacts of climate change and socioeconomic development (Doctoral thesis summary)Vietnam Academy of Sciences and Technology, 28.

24. Truong, M.H., Nguyen, V.L., Ta, T.K.O., Takemura, J., 2011. Changes in late PleistoceneHolocene sedimentary facies of the Mekong River Delta and the influence of sedimentary environment on geotechnical engineering properties: Engineering Geology, 122 (3-4): 146-159.

25. Wang, J.J., Lu, X.X., Kummu, M., 2011. Sediment load estimates and variations in the Lower Mekong River: River Research and Applications, 27 (1): 33-46.

26. World Bank, 2016. Migration and Remittances: Recent Developments and Outlook: Publishing and Knowledge Division, The World Bank.

27. Yadu,P., Mateo, B., Jacob, R., Hyunwoo, K., Venkataramana, S., David, H., 2018. A Review of the Integrated Effects of Changing Climate, Land Use, and Dams on Mekong River Hydrology. Water, 10 (3): 266. 